\title{
JPR continues to grow as a leading dental journal and international public asset
}

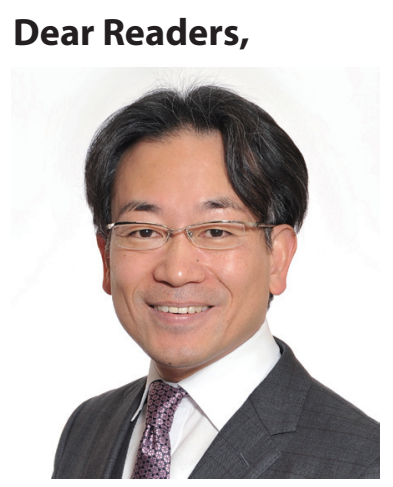

I am honored and humbled to serve as the new Editor-in-Chief of the Journal of Prosthodontic Research $(J P R)$, starting with this issue in 2021. To start with, I am happy to announce that our editorial committee has just launched with exciting news, receiving a new journal impact factor of 4.642 (Journal Citation Reports, Clarivate Analytics). Now, JPR is ranked $12^{\text {th }}$ out of 91 journals within the category of "Dentistry, Oral Surgery \& Medicine." It is worthwhile to note that JPR has ranked in the top $25 \%$ of its category (Q1) over a 5-year period, which is indicative of its global scientific recognition not only in prosthodontics but also in dentistry overall. With deep respect and gratitude, I thank the past Editors-inChief and committee members of JPR for their great efforts to build such a legacy.

Given the increasing diversity in prosthodontic research [1], JPR now has a wide spectrum of targeted research fields [2]. The journal's comprehensive aim and scope have consequently encouraged interdisciplinary prosthodontic research, with collaboration among medical, engineering, informatics, nutrition and dental sciences $[3,4]$. The JPR committees have also continued to create many action plans for JPR's sustained progress [5]. These strategies and efforts have contributed to $J P R$ 's ascension as a worldwide first-class dental journal [6].

Our journal will continue to evolve in step with global society, including its adoption of smart digital technologies. However, wealth disparity impedes democratized access to such technologies, and this is only exacerbated by emerging global issues such as the COVID-19 pandemic and unprecedented population aging [7]. In academia, the financial burden of article subscription fees is already a problem, particularly in low- and middle-income countries.

In accordance with the times, I would like to support, as Editorin-Chief, fully open access to JPR [8] to advance scientific knowledge by making it freely accessible to all stakeholders. As a result, I hope that rather than just achieving higher journal metrics and rankings, $J P R$ will become a flagship for the internationalization of the prosthodontic community and an international public asset that creates new societal value.

$J P R$ has continued to grow in terms of its diversity and inclusiveness $[9,10]$. I would like to continue that growth, to make JPR a journal that is universally respected not only for the quality of its scientific standards but also for its contribution to the academic society. To achieve that, we already have most powerful tools here: our editorial board members, authors, reviewers, and readers in our community. We will continue to develop JPR by updating the features of the journal with shining scientific contents, which could break new barriers in prosthodontic research and effectively contribute to worldwide open science.

Lastly, on behalf of the current committee members, I thank all of the people and societies who have been involved with JPR for their continued support and confidence in our journal.

Sincerely,

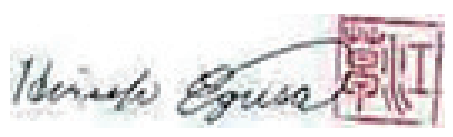

Prof. Hiroshi Egusa DDS, PhD

Editor-in-Chief

Journal of Prosthodontic Research

Division of Molecular and Regenerative Prosthodontics, Tohoku University Graduate School of Dentistry, Sendai, Miyagi 980-8575, Japan

\section{REFERENCES}

[1] Egusa H. Increasing diversity in prosthodontic research. J Prosthodont Res. 2014;58:191-2. https://doi.org/10.1016/j.jpor.2014.08.002, PMID:25311990

[2] Egusa H. Another year of growth for the Journal of Prosthodontic Research. J Prosthodont Res. 2016;60:1-2. https://doi.org/10.1016/j.jpor.2015.12.002

[3] Kuboki T. A prosthodontic medicine with collaboration between medical and dental sciences. J Prosthodont Res. 2012;56:227-8. https://doi. org/10.1016/j.jpor.2012.10.002, PMID:23137672

[4] Hosokawa R. Nutrition: its importance in prosthetic dentistry.J Prosthodont Res 2020;64:vi-vii. https://doi.org/10.1016/S1883-1958(20)30033-5

[5] Egusa H. Progress of the Journal of Prosthodontic Research under the fouryear action plan. J Prosthodont Res. 2017;61:231-2. https://doi.org/10.1016/j. jpor.2017.06.003, PMID:28709574

[6] Ohkawa S. New start as a global academic journal of JPR. J Prosthodont Res. 2021;65(1):vi. https://doi.org/10.2186/jpr.65.1_vi, PMID:33627539

[7] Tada S. Ageing partially edentate patients: how can we control the maintenance burden? J Prosthodont Res 2020;64:vi. https://doi.org/10.1016/ S1883-1958(20)30111-0

[8] Hosokawa R. Beginning of JPR's great voyage to the open science world. J Prosthodont Res. 2021;65(2):vi. https://doi.org/10.2186/jpr.65.2_vi, PMID:34193772

[9] Baba K. Journal of Prosthodontic Research in great shape and continues to grow. J Prosthodont Res. 2013;57:151-2. https://doi.org/10.1016/j. jpor.2013.06.001, PMID:23838064

[10] Matsumura H. Development of JPR in JCR as a phoenix. J Prosthodont Res. 2015;59:159-60. https://doi.org/10.1016/j.jpor.2015.04.001

Received 14 July 2021, Accepted 15 July 2021, Available online 21 August 2021

DOI: https://doi.org/10.286/jpr.JPR_65_3_ed

Copyright: @ 2021 Japan Prosthodontic Society. All rights reserved.

This is an open-access article distributed under the terms of Creative Commons Attribution License 4.0 (CCBY 4.0), which allows users to distribute and copy the material in any format as long as credit is given to the Japan Prosthodontic Society. 